\title{
Effects of Six Weeks Combined Training Program on Hematological Parameters in Elite Basketball Players
}

\author{
${ }^{1}$ Mohammad Talaee ${ }^{*},{ }_{1}^{1}$ Farzad Nazem, ${ }^{2}$ Seyed Jalal Taherabadi, ${ }^{3}$ Sima Sajadi \\ ${ }^{1}$ Department of Exercise Physiology, Faculty of Sport Science, Bu-Ali-Sina University, Hamedan, Iran. ${ }^{2}$ Department \\ of Sport Science, Faculty of Literature \& Humanities, Lorestan University, Khoramabad, Iran. ${ }^{3}$ Department of \\ Physical Education and Sport Science, Asadabad Branch, Islamic Azad University, Hamadan, Iran.
}

\begin{abstract}
Background. In team sports, according to perform variety of motor skills, development of special bio-motor abilities and imposed proper exercise stress, hematologic adaptations following exercise will be different.

Objectives. Therefore, the aim of this study was the effects of six weeks combined training program on hematological parameters in elite basketball players.

Methods. Fifteen athletes from 30 qualified players for basketball playoff league, with the average age of $(24 \pm 1 / 5)$ years, selected randomly and they were participated in 6 weeks ( 3 sessions per week) of combined training (circular resistance training and basketball special-skills). Blood samples were drawn in the fasting state for Three times: before, after and 24 recovery hours in order to measure the hematologic parameters (red and white blood cells, hemoglobin, hematocrit, MCV, PLT, MCH, MCHC, plasma volume).

Results. Significant increase in the white blood cells and platelet counts were obtained, in two stages; after and 24 hours recovery times. While the levels of hemoglobin, hematocrit, and number of red blood cells (RBC) were decreased after 24 hours of recovery significantly. The significant changes weren't observed in MCH, MCHC, MCV and plasma volume factors following the combined training program.

Conclusion. Performing combined training plays an important role in physiological and hematological adaptations processes and promotion athletic performance. While, prescription this method of training must be associated with regularly biochemical blood monitoring to balance between exercises stress and recovery strategies.
\end{abstract}

KEY WORDS: Combined Training, Blood Cells, Plasma Volume, Hemoglobin, Blood Platelets.

\section{INTRODUCTION}

The dominating content of body fluids is water. Approximately $60-65 \%$ of body water is contained within the cells that are separated from external environment by cell membrane (in intracellular fluid) with the other $35-40 \%$ of body water contained outside the cells in extracellular fluid(1). The cytosol or ICF is a complex mixture of substances dissolved in water. Although water forms the large majority of the cytosol, its structure and properties within cells is not well understood. The concentrations of ions such as sodium and potassium are different in the cytosol than in the extracellular fluid; these differences in ion levels are important in processes such as osmoregulation, cell signaling, and the generation of action potentials in excitable cells such as endocrine, nerve and muscle cells(2). Extracellular fluids

*. Corresponding Author:

Mohammad Talaee

E-mail: mohammadtalaee64@yahoo.com 
collectively are the all fluids that are in the outside of cells that make up about one-third of body water as well as Extracellular fluid, in conjunction with intracellular fluid, helps control the movement of water and electrolytes throughout the body. In order to maintain osmotic balance, the extracellular compartments of a mammal's body must be able to excrete and absorb water to and from the environment. In addition inorganic ions must also be exchanged between ECF and the external environment to maintain homeostasis(3). Blood is a bodily fluid in animals that consists of 4 to 5 percent of our body weight and is divided in two parts; plasma and blood cells that delivers necessary substances such as nutrients, hormones and oxygen to the cells and transports metabolic waste products away from activated tissues(4). Participating in Physical activity and exercise training with the purposes of increasing aerobic capacity, body endurance; depends on various factors, one of the most important indicators of physiological adaptations followed by training, is improving the oxygen carrying capacity by red blood cells. Several Parameters such as numbers of red blood cells, hemoglobin and hematocrit levels and plasma volume play key role in supply oxygen and disposal $\mathrm{CO} 2$ from active tissues. It appears that these changes may influences on athletic performance, recovery and long-term compatibility $(5,6)$. Various studies have investigated the changes of blood components following different exercise $\operatorname{program}(7,8)$. In line with the results of this study, Field, Gougeon and Marliss (1991) were reported double raise of White Blood Cells (WBC) number after two exhaustive stationary bike training session(9). Beside, Havil, Ebrahim , Aslankhani (2003) and Nemet, Mills, Cooper (2004) revealed significantly increased in the amount of WBC, after a progressively aerobic exercise and wrestling training sessions $(10,11)$. As well as Nielsen Secher, Perdersen(1996) found that 3-fold increase in WBC levels after two training sessions of professional sailing(12). Ronsen, Krach, Haugh (2002) and Gleeson (2007) expressed significantly increased the number of WBC after two sessions of intense endurance training (with an intensity of $75 \%$ VO2 max)(13, 14). But Robson-Ansley, Blannin, Gleeson (2007) were not observed dramatic changes in the number of WBC plasma after three consecutive of endurance training sessions(15). Boyajiev,Taralov, (2000) reported a significantly increased in the number of Red Blood Cells (RBC) in young boys and girls followed by submaximum training(16). Ahmadizad et al, (2003); were expressed significantly increased in platelet counts and meaning of plasma volume after three types of endurance training with different intensities(17). also Wu et al (2004); were not observed the significantly increased in the number of WBC, PLT and other blood factors after 24 hours of endurance exercise(6). Karacok and Dressendorfer $(2005,1991)$ in their studies, were reported significantly reduced in hemoglobin levels and MCV and an increased the number of PLT and WBC after 90 minutes of football practice, but the RBC changes wasn't significant $(18,19)$. As well as Stojic et al (2002); in compared two control and trained groups, weren't expressed significant changes in hemoglobin and hematocrit levels(20). Review of scientific evidence shown that; there are inconsistent and limited scientific information related to hematology changes following the implementation of special training program (in respects of intensity and duration of exercise) during a specified period of time. The majority of studies are related to the effects of a training session (resistance or aerobic) and competition(16, 21). Due to time constraints in the preparation of athletes, participating in appropriate training volume and intensity (effective metabolic stress and mechanical work) is possible only by multiple intense daily training sessions. Also, scientific evidence showed that combines training as an accredited training method implies on implementation of two type of training protocol with different purposes, such as strengthening the muscles, increase cardiorespiratory endurance and sport specific skills during a training session. However, the physiological consequences of combined training may have significant effects on hematologic changes that influence optimal athletic performance. Therefore, despite the results of studies that have done related to this topic, but direct influences of blood factors changes on athletic performance profile in different sports is unclear. So, the purpose of this 
study was to evaluate the hematological factors changes followed six weeks of combined training (circuit resistance and sport-specific skills training of basketball) at two times; in the morning and afternoon among basketball players before participating in their main tournament.

\section{MATERIALS AND METHODS}

Participants. Fifteen male players on average of $24 \pm 1.5$ year's old and anthropometrical characteristics average of (weight $83 \pm 3.3 \mathrm{~kg}$, height $188 \pm 6.1 \mathrm{~cm}$, body fat percentage of $11.7 \pm 2.04$ and the body mass index of $23.4 \pm 2.03 \mathrm{~kg} / \mathrm{m}^{2}$ ) were selected from the 30 elite basketball player's playoff League population randomly. Each subject read and signed a written informed consent and completed medical history questionnaire. Medical clearance, carried out by qualified practitioner in order to lack of any metabolic, hematological, infections, allergies and cardiovascular diseases. Subjects not smoking and taking any energetic and sport supplements within the last three months before and during research.

Measurements. The anthropometric characteristics of the subjects were including body weight (was measured by Seca digital scale made in Chinese with 100 gr of measurement accuracy), Stature (was measured by Seca wall stature gauge with measurement accuracy of 0.1 $\mathrm{cm}$ ), body mass index (was calculated by dividing weight to height square), body fat percentage estimation (was calculated by using mechanical Harpenden caliper with 6 points with tipton regression equation) (22).

Body Fat percentage $=($ chest $\times 0.148)+$ $($ subscapular $\times 0.075)+($ triceps $\times 0.77)+$ $($ superiliac $\times 0.16)+($ abdominal $\times 0.152)+$ (thigh $\times 0.102$ )
In order to measurement maximum oxygen consumption (Vo2max) in two stages (pre-post), submaximal Fox ergometer test with the reliability measurement standard error of $8.7 \pm \%$ and the correlation coefficient of $(r=0.76$ standard method of estimation method) was used. At the first subjects must pedal for 5 minutes continuously on a stationary bike with consistent intensity of 150 watts (cadence around the 50 to 60 flywheel per minute) (23).

$\mathrm{VO}_{2 \max }(\mathrm{ml} / \mathbf{k g} / \mathbf{m i n})=(6300-19.26)$ (recorded 5 minute heart rate)

For measuring of one repetition maximum (1RM), after 10 minute General muscles warming-up, one repetition maximum was calculated by Brzycki formula (lower than10 repetitions) in the performance of bench press, curls arm, triceps extension, knee flexion, knee extension, leg press and Lat pull-down cable exercises (24).

$1 \mathrm{RM}=($ weight $) /(1.0278 \times$ repetitions $)$

Exercise program. Participants were informed and guided about the training program completely. Then, circuit resistance training protocol was performed under the supervision of a qualified coach for 40 minutes in the morning and 60 minutes of basketball specialized skills training in afternoon. As participants warm up their body for 15 minutes at 65 to 70 percent of maximum heart rate, then performing circuit resistance training at seven stations (bench press, biceps curl, triceps extension, knee flexion, knee extension, leg press, lateral raise) in the sequence of 1 minute training (with 40 to $95 \%$ of one repetition maximum) and 1 minute of rest for three times at $10 \mathrm{AM}$. Three minutes rest was considered between each circuit. As well as players performed specific basketball skills (techniques and tactics) training for 60 minutes with intensity of 65 to 85 percent of maximum heart rate in afternoon (Table 1).

Table 1. Training variable changes during six weeks of combined training

\begin{tabular}{cccc}
\hline Weeks & \%1RM & Set $\times$ Rep & \%MHR \\
\hline $\mathbf{1 - 2}$ & $40-60$ & $3 \times 15-20$ & $65-75$ \\
\hline $\mathbf{3 - 4}$ & $65-75$ & $4 \times 10$ & $75-85$ \\
\hline $\mathbf{5 - 6}$ & $85-95$ & $4 \times 3$ & 85 \\
\hline
\end{tabular}

Physical Activity and Daily Nutritional Statutes. Nutritional status and diet are key factors that influence on research results. Amount of calories consumption of participants 
during six-weeks of exercise protocol was monitored by Supervision of Nutritionist and by using Food analyzer software. The average of calorie intake (with a combined of 62 percent carbohydrate, 22 percent fat and 18 percent protein) was calculated daily equivalent to $4200 \pm 101 \mathrm{kcal}$ (figure 1). In order to eliminate the possible impact of dehydration on hematological parameters, the subjects were instructed to drink sufficient water and also to refrain from strenuous exercise during 24 hours prior to collection of blood samples.

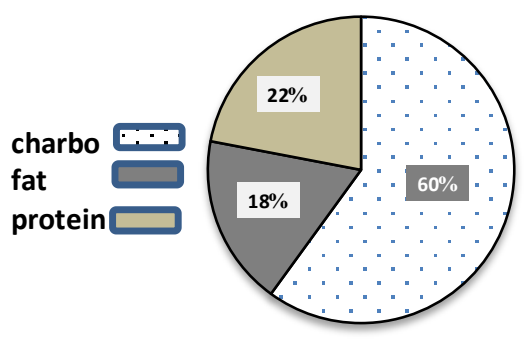

Figure1. Food composition of players during 6 week of training program.

Blood Sampling and Laboratory Analysis. In order to study Hematologic parameters following exercises protocol, blood samples were collected in fasting statue from right antecubital vein in three stages before, after and 24 hours of recovery times, Then blood samples were collected and transferred by a vial containing K3EDTA (anticoagulant agent) to the Central Medical Laboratory immediately. hematological parameters including red blood cell count (RBC), hemoglobin $(\mathrm{Hb})$, hematocrit (Hct), mean red cell volume (MCV), mean red cell hemoglobin $(\mathrm{MCH})$, white blood cell (WBC), blood platelets (PLT), mean red cell hemoglobin concentration (MCHC) were analyzed using an automated cell counter(Sysmex, Japan).

Statistical Analysis. The data were expressed as mean and standard deviation. After determining the normal distribution of data (KolmogorovSmirnov test) and Homogeneity of variance) Leven-test) as well as in purpose to comparison the selected hematological Parameters that mentioned above in three interval times (before, after and 24 hours recovery) one-way repeated measures (ANOVA) was performed. Dependent t-test was used to determine significant differences existed between data in two times (pre \& post).the significant level was set at $\mathrm{p}<0.05$. All analyses are carried out using SPSS (18.0).

\section{RESULTS}

The findings of this study, showed that Anthropometric factors, (weight, body mass index and body fat percentage) Physiological (maximum oxygen consumption, and 1 Repetition Maximum) and Hematological (RBC, WBC, PLT, hemoglobin and hematocrit) were changed significantly $(\mathrm{p}<0.03)$ (Tables $2,3,4$ and 5). While, the Levels of WBC, PLT, increased significantly within 24 hours of recovery and after the exercise protocol respectively. Likewise, the $\mathrm{RBC}$, hematocrit and Hemoglobin factors were reduced significantly after 24 hours of recovery time $(\mathrm{p}<0.03)$. In addition, no significant changes were observed in the (MCH, MCV, MCHC and plasma volume) parameters after the implementation of combined training program.

Table 2. Anthropometric and physiologic characteristics of subjects in two stages of exercise protocol

\begin{tabular}{ccccccc}
\hline & Vo2max (ml/kg/min) & Age (year) & Height $(\mathbf{c m})$ & Weight $(\mathbf{k g})$ & BMI $\left(\mathbf{k g} / \mathbf{m}^{2}\right)$ & BF (\%) \\
\hline Pre- test & $56.16 \pm 5.03$ & \multirow{2}{*}{$24 \pm 1.5$} & \multirow{2}{*}{$188 \pm 6.1$} & $83 \pm 3.3$ & $23.4 \pm 2.03$ & $11.7 \pm 2.04$ \\
\cline { 1 - 4 } Post- test & $61.12 \pm 4.01^{*}$ & & & $80 \pm 3.2^{*}$ & $22.6 \pm 2.1$ & $10.3 \pm 2.02$ \\
\hline
\end{tabular}

Table 3. Subject's one repetition maximum estimated in circuit resistance training before and after the implementation of the training protocol.

\begin{tabular}{llllllll}
\hline & $\begin{array}{l}\text { Lateral } \\
\text { raise }\end{array}$ & $\begin{array}{l}\text { Knee } \\
\text { flexion }\end{array}$ & $\begin{array}{l}\text { Knee } \\
\text { extension }\end{array}$ & Leg press & $\begin{array}{l}\text { Triceps } \\
\text { extension }\end{array}$ & $\begin{array}{l}\text { Biceps } \\
\text { curls }\end{array}$ & Bench press \\
\hline Pre & $21 \pm 3.4$ & $41 \pm 4.4$ & $66 \pm 5.5$ & $186 \pm 10.2$ & $32 \pm 2.1$ & $40 \pm 6.1$ & $80.5 \pm 10.1$ \\
\hline Post & $29.5 \pm 4.1$ & $52 \pm 6.2$ & $83 \pm 6.1$ & $244 \pm 14.8$ & $38 \pm 3.1$ & $47 \pm 4.2$ & $89.5 \pm 11.9$ \\
\hline
\end{tabular}


Table 4. The changes profile of hematologic parameters in three stages following combined training protocol

\begin{tabular}{cccccc}
\hline & Value & Pre-test & Post-test & 24 h after Recovery & P-value \\
\hline WBC & $10^{3} / \mu 1$ & $7.11 \pm 0.41$ & $8.13 \pm 0.32$ & $8.86 \pm 0.46$ & $0.03^{*}$ \\
\hline RBC & $10^{6} / \mu 1$ & $6.25 \pm 0.11$ & $5.12 \pm 0.21$ & $5.14 \pm 0.10$ & $0.02^{*}$ \\
\hline HCT & $\%$ & $46.42 \pm 0.47$ & $46.32 \pm 0.21$ & $45.14 \pm 0.10$ & $0.02^{*}$ \\
\hline HGB & $\mathrm{g} / \mathrm{L}$ & $16.18 \pm 0.12$ & $16.65 \pm 0.08$ & $15.33 \pm 0.06$ & $0.02^{*}$ \\
\hline PLT & $10^{3} / \mu 1$ & $218.15 \pm 17.4$ & $238.13 \pm 11.2$ & $226 \pm 14.10$ & $0.00^{*}$ \\
\hline PV & $\%$ & $54.25 \pm 2.1$ & $54.12 \pm 2.3$ & $55.10 \pm 2.1$ & 0.26 \\
\hline MCH & $\mathrm{pg}$ & $26.44 \pm 2.1$ & $27.12 \pm 1.2$ & $27.22 \pm 1.02$ & 0.30 \\
\hline MCHC & $\mathrm{g} / \mathrm{dl}$ & $35.11 \pm 1.1$ & $35.22 \pm 0.8$ & $35.17 \pm 0.1$ & 0.41 \\
\hline MCV & FL & $87.24 \pm 2.1$ & $86.13 \pm 2.03$ & $86.43 \pm 2.2$ & 0.23 \\
\hline
\end{tabular}

$* \mathrm{p}<0.05$ considered significant, MCH (Mean corpuscular Hemoglobin), MCHC (Mean corpuscular Hemoglobin concentration), MCV (Mean corpuscular volume), PV (Plasma volume)

Table 5. Compared hematological parameters profile in three stages of combined training (Bonferroni-test)

\begin{tabular}{cccccccc}
\hline \multirow{2}{*}{ Variables } & & \multicolumn{2}{c}{ Mean Difference } & \multicolumn{2}{c}{ SE } & \multicolumn{2}{c}{ P-value } \\
\cline { 3 - 8 } & & post & $\mathbf{2 4 h}$ & post & $\mathbf{2 4 h}$ & post & $\mathbf{2 4 h}$ \\
\hline WBC $\left(\times \mathbf{1 0}^{\mathbf{3}} / \boldsymbol{\mu l}\right)$ & Pre & -0.69 & -1.06 & $.44 \cdot$ & 0.33 & 0.40 & $\mathbf{0 . 0 2} *$ \\
\hline RBC $(\times \mathbf{1 0} / \boldsymbol{\mu l})$ & Pre & 0.06 & 0.14 & 0.00 & 0.04 & $0.04^{*}$ & $\mathbf{0 . 0 0}^{*}$ \\
\hline HCT $(\boldsymbol{\%})$ & Pre & 0.34 & 2.13 & 0.04 & 0.18 & 0.60 & $\mathbf{0 . 0 0 *}$ \\
\hline HGB $(\mathbf{g} / \mathbf{L})$ & Pre & 0.09 & 0.39 & 0.02 & 0.03 & 0.70 & $\mathbf{0 . 0 1}$ \\
\hline PLT $\left(\times \mathbf{1 0}^{3} / \boldsymbol{\mu L}\right)$ & Pre & -3.40 & -6.80 & 7.43 & 4.33 & $0.02^{*}$ & $\mathbf{0 . 4 0}$ \\
\hline
\end{tabular}

$* \mathrm{p}<0.05$ considered significant

\section{DISCUSSION AND CONCLUSION}

This study was conducted to determine, hematological parameters (WBC, RBC, HCT, $\mathrm{HGB}, \mathrm{MCH}, \mathrm{MCHC}, \mathrm{MCV}, \mathrm{PL}$ and PV) changes following combined training protocol (circuit training and basketball specific- skills practice). We found a significant increase in the number of white blood cells at 24 hours of recovery time (figure-2). May different mechanisms explained the changes pattern of white blood cells following exercise. Leukocytosis phenomenon is one of the most considerable changes in the circulatory system after intense and moderate exercise. This situation was maintained at high level for a long period of time after the workout $(25,26)$. It seems that leukocytosis levels are associated directly with the intensity and duration of exercise and it has inverse relationship with the physical fitness levels(27). On the other hand, these increases were attributed to hormonal changes, particularly the activation of the hypothalamic-pituitary axis and corticosteroids hormones in response to exercise, immune cells distribution, increased blood flow, inflammatory response to tissue injuries $(5,28)$. The results of present study were in line with, Field, Ronsen, Niemann, Karakok and Gleeson findings $(9,13,14,19,29)$. In contrast, Duca et al, weren't reported, significant changes in the number of WBC after $48 \mathrm{~h}$ recovery(30). As well as, the mean changes in plasma volume of basketball players was not significant in the three period of before and two recovery times. These findings indicated that the volume of blood plasma concentrations remained Constancy after combined exercise program. It is possible that several factors such as adequate fluid replacement and physiological adaptations in response to exercise (based on intensity and duration of training) may prove the unchanged levels of plasma volume along with exercise. The platelet counts were significantly increased in line with the results of Karakok after combined exercise. Because it seems that the platelets level of blood increased under the circumstance of exercise, physiological arousal and sympathetic nervous system activity (17, 19, 31). Similar findings have been observed 
among professional cyclists during races and during maximal isometric exercise $(32,33)$.

Also this is probably due to release fresh platelets from spleen (stored one-third of body platelets), bone marrow and lungs in response to epinephrine stimulation. The other effective mechanism that stimulates blood clotting system potentially by platelet in response to tiny tissue damage is intensity of training(34). In line with this study, Moore et al, weren't reported significant differences in levels of $\mathrm{MCH}, \mathrm{MCHC}$ and MCV after exhaustive exercise training(35). In addition Gaeini, Wu weren't observed dramatic changes in hematologic parameters $(\mathrm{MCH}, \mathrm{MCHC}, \mathrm{RBC}$ and MCV) after exercise(3, 6). These unchanged of hematological factors can conclude due to physiological adaptations that occur with exercise while fall in RBC count could be attributed to either intravascular hemolysis from mechanical trauma, osmotic/oxidative damage to erythrocytes or gastrointestinal bleeding $(3,6,36)$. Other findings of this study reveal that the number of red blood cells, hemoglobin and hematocrit levels of basketball players have declined after combined training.

Yalcin and their colleagues, demonstrated reduced and destructed of red blood cells immediately after a session of intense activity(37). Strenuous exercise causes structural changes/damages to the RBC membrane resulting in the preferential hemolysis of older RBCs. The proportionately greater number of young and more deformable RBC's in the circulation may be reflected as increased MCV(36). Also, in study of Boyali et al, the hematocrit and RBC changes were not significant after a session of the taekwondo competition(38). In addition, Atan and Alacam were indicated significant increase changes after acute aerobic an anaerobic exercise(7). According to numerous studies, these changes of hematological factors may cause: reduced oxygen delivery to the target tissues and expulsion rate of $\mathrm{CO}_{2}$ from activated muscles, Lack and decreased of oxygen available to the recruited muscle, changed the energy metabolism dependent on anaerobic resources that ultimately leads to produce lactic acid, rapid depletion of energy reserves, fatigue and impaired entire athletic performance(39, 40). According to findings of several studies; hemoglobin and hematocrit levels decreased in peripheral blood flow and blood cells damaged following intense exercise that companied with increased lactic acid and Red cell membrane deformity seen post (strenuous) exercise might be due to oxidative stress leading to hemolysis thus increasing Hemopoiesis (more young erythrocytes in the circulation) to meet the demand for oxygen transport(41, 42). Interestingly, in this study associated with decreased levels of red blood cells and hematocrit, the mean changes of maximum oxygen consumption were observed significantly. It seems that different physiological mechanisms may contribute to improved cardiopulmonary endurance (cellular adaptations, sport economy, reduce perception of fatigue, increased lactate threshold and availability of substrates).

According to the results of this and other studies; decreased of red blood cells, increased clotting factors and immune cells levels following combined training, it concluded that all of these factors are effective in the exchange of respiratory gases, oxygen supply to active muscles, energy metabolism, recovery rate, athletic performance, body health and adaptation processes. Some athletes face to time constraints between the activities for psychological recovery and return to the initial state before the next activity. In some sports such as wrestling, basketball and athletics track, athletics have to do heavy work on consecutive days or even in a day. And this issue has caused a lot of pressure on the body system(43). On the other hand, research's findings have shown that monitoring the hematological changes at regular intervals in specific preparation and competition phases can directly or indirectly considered as important indicators of athletes adaptation statue based on imposed stress trainings(44-46). The most common challenge for educators is to determine the type, intensity, frequency and duration of exercise appropriately. Therefore, from standpoints of hematologic considerations; despite the considerable role of combined training as valid and well-documented training method in preparing and promotion athletic performing, 
this type of training in two stages (in the morning and evening) imposed excessive training stress(metabolic and mechanical) on athletes organisms. As a result; maintaining proper balance between intensive exercise and recovery, periodization of training and monitoring biochemical markers; appears to be vitally important in view of such a considerable training load. Too heavy an exercise load and too short a recovery period can lead to the accumulation of unfavorable training outcomes (increased risk of over training and decreased athletic performance).

\section{ACKNOWLEDGEMENT}

This work was supported by Hamedan BuAli-Sina University. We are indebted to those basketball players who donated their valuable blood for our study, and we are grateful to the head and staffs of the biochemistry-laboratory of medical sciences for their cooperation. Eventually, Authors would like to acknowledge all the participants who made this research possible.

\section{APPLICABLE REMARKS}

- Combined training imposed too much training stress on physiological systems.

- Paying more attention to recovery strategies and monitoring biochemical factors regularly, during this type of reliable training method is so important.

\section{REFERENCES}

1. Craig S, Byrnes W, Fleck S. Plasma volume during weight lifting. International journal of sports medicine. 2008;29(2):89-95.

2. Szygula Z. Erythrocytic system under the influence of physical exercise and training. Sports Medicine. 1990;10(3):181-97.

3. Gaeini A. Comparing the effect of a maximal exercise and exercise under maximal on the response hematological factors of adolescent athletes and non athletes. J Mov. 2001;10:125-35.

4. Viru AA, Viru M. Biochemical monitoring of sport training: Human Kinetics; 2001.

5. Koike Y, Isozaki A, Nomura Y, Fujitsuka S. Effect of 12 weeks of strenuous physical training on hematological changes. Military medicine. 2005;170(7):590.

6. Wu H-J, Chen K-T, Shee B-W, Chang H-C, Huang Y-J, Yang R-S. Effects of $24 \mathrm{~h}$ ultra-marathon on biochemical and hematological parameters. World Journal of Gastroenterology. 2004;10(18):2711-4.

7. Atan T, Alacam H. The Effects of Acute Aerobic and Anaerobic Exercise on Blood Parameters. Anthropologist. 2015;19(1):87-93.

8. Gnanou J, Caszo B, Khalin I, Leong S, Knight VF, Bidin MZB. The effect of 6-weeks military training on blood hematological parameters in untrained recruits in a military university. Medicine Science. 2014;3(3):1479-90.

9. Field CJ, Gougeon R, Marliss EB. Circulating mononuclear cell numbers and function during intense exercise and recovery. Journal of applied physiology. 1991;71(3):1089-97.

10. Ebrahim k, Havil F, Aslankhani M. Effect of a single-session progressive aerobic training on the immune system of young and adult athletes. Journal of Movement. 2003;17:25-43.

11. Nemet D, Mills P, Cooper D. Effect of intense wrestling exercise on leucocytes and adhesion molecules in adolescent boys. British journal of sports medicine. 2004;38(2):154-8.

12. Nielsen HB, Secher NH, Christensen NJ, Pedersen BK. Lymphocytes and NK cell activity during repeated bouts of maximal exercise. American Journal of Physiology-Regulatory, Integrative and Comparative Physiology. 1996;271(1):R222-R7.

13. Gleeson M. Immune function in sport and exercise. Journal of applied physiology. 2007;103(2):693-9.

14. Ronsen O, Kjeldsen-Kragh J, Haug E, Bahr R, Pedersen BK. Recovery time affects immunoendocrine responses to a second bout of endurance exercise. American Journal of Physiology-Cell Physiology. 2002;283(6):C1612C20.

15. Robson-Ansley PJ, Blannin A, Gleeson M. Elevated plasma interleukin-6 levels in trained male triathletes following an acute period of intense interval training. European journal of applied physiology. 2007;99(4):35360. 
16. Boyadjiev N, Taralov Z. Red blood cell variables in highly trained pubescent athletes: a comparative analysis. British journal of sports medicine. 2000;34(3):200-4.

17. Ahmadizad S, El-Sayed MS. The effects of graded resistance exercise on platelet aggregation and activation. Medicine and science in sports and exercise. 2003;35(6):1026-32.

18. Dressendorfer R, Keen C, Wade C, Claybaugh J, Timmis G. Development of runner's anemia during a 20-day road race: effect of iron supplements. International journal of sports medicine. 1991;12(3):332-6.

19. Karakoc Y, Duzova H, Polat A, Emre M, Arabaci I. Effects of training period on haemorheological variables in regularly trained footballers. British journal of sports medicine. 2005;39(2):e4-e.

20. Ostojic S. Antropometric, physiological and biochemical characteristics of elite Yugoslav soccer players: Doctoral thesis, Medical faculty, University of Belgrade, Belgrade. 1-182.(In Serbian: English abstract) 2002; 2002.

21.El-Sayed MS, Ali N, Ali ZE-S. Haemorheology in exercise and training. Sports Medicine. 2005;35(8):649-70.

22. Tcheng T-K, Tipton CM. Iowa wrestling study: anthropometric measurements and the prediction of a" minimal" body weight for high school wrestlers. Medicine and science in sports. 1972;5(1):1-10.

23. Sartor F, Vernillo G, de Morree HM, Bonomi AG, La Torre A, Kubis H-P, et al. Estimation of maximal oxygen uptake via submaximal exercise testing in sports, clinical, and home settings. Sports medicine. 2013;43(9):86573.

24. Brzycki M. Strength testing - predicting a one-rep max from reps-to-fatigue. Journal of Physical Education, Recreation \& Dance. 1993;64(1):88-90.

25. Arazi H, Damirchi A, Mostafaloo A. Variations of hematological parameters following repeated bouts of concurrent endurance-resistance exercises. 2011.

26. Cakir-Atabek H, Atsak P, Gunduz N, Bor-Kucukatay M. Effects of resistance training intensity on deformability and aggregation of red blood cells. Clinical hemorheology and microcirculation. 2008;41(4):251-61.

27. Antosiewicz J, Kaczor JJ, Kasprowicz K, Laskowski R, Kujach S, Luszczyk M, et al. Repeated "all out" interval exercise causes an increase in serum hepcidin concentration in both trained and untrained men. Cellular immunology. 2013;283(1):12-7.

28. Perez CJ, Nemet D, Mills PJ, Scheet TP, Ziegler MG, Cooper DM. Effects of laboratory versus field exercise on leukocyte subsets and cell adhesion molecule expression in children. European journal of applied physiology. 2001;86(1):34-9.

29. Nieman D, Simandle S, Henson D, Warren B, Suttles J, Davis J, et al. Lymphocyte proliferative response to 2.5 hours of running. International journal of sports medicine. 1995;16(6):404-9.

30. Duca L, Da Ponte A, Cozzi M, Carbone A, Pomati M, Nava I, et al. Changes in erythropoiesis, iron metabolism and oxidative stress after half-marathon. Internal and emergency medicine. 2006;1(1):30-4.

31. Rebelo A, Candeias J, Fraga M, Duarte J, Soares J, Magalhaes C, et al. The impact of soccer training on the immune system. The Journal of sports medicine and physical fitness. 1998;38(3):258-61.

32. Ricci G, Masotti M. Effects of exercise on platelet indices in well-trained athletes. Thrombosis research. 1989;56(6):767-8.

33. Röcker L, Günay S, Gunga H, Hopfenmüller W, Ruf A, Patscheke H, et al. Activation of blood platelets in response to maximal isometric exercise of the dominant arm. International journal of sports medicine. 2000;21(3):191-4.

34. Brun J, Khaled S, Raynaud E, Bouix D, Micallef J, Orsetti A. The triphasic effects of exercise on blood rheology: which relevance to physiology and pathophysiology? Clinical Hemorheology and Microcirulation. 1998;19:89104.

35. Moore RJ, Friedl KE, Tulley RT, Askew EW. Maintenance of iron status in healthy men during an extended period of stress and physical activity. The American journal of clinical nutrition. 1993;58(6):923-7.

36. Robinson Y, Cristancho E, Boning D. Intravascular hemolysis and mean red blood cell age in athletes. Medicine and science in sports and exercise. 2006;38(3):480.

37. Yalcin O, Erman A, Muratli S, Bor-Kucukatay M, Baskurt OK, Turkey A. Time course of hemorheological alterations following heavy anaerobic exercise in untrained human subjects. Journal Applied Physiology. $2002 ; 10$.

38. Boyali E, Cakmakcı O, Patlar SCE. Effects Of Camp Term On Some Hematological Parameters In Male Taekwondoers. Uluslararası Spor Bilimleri Kongresi bildiri kitab1, Mugla. 2009;6:280-1.

39. Bonsignore MR, Morici G, Santoro A, Pagano M, Cascio L, Bonanno A, et al. Circulating hematopoietic progenitor cells in runners. Journal of Applied Physiology. 2002;93(5):1691-7. 
40. Schumacher YO, Temme J, Bueltermann D, Schmid A, Berg A. The influence of exercise on serum markers of altered erythropoiesis and the indirect detection models of recombinant human erythropoietin abuse in athletes. haematologica. 2003;88(6):712-4.

41. Schumacher YO, Jankovits R, Bültermann D, Schmid A, Berg A. Hematological indices in elite cyclists. Scandinavian journal of medicine \& science in sports. 2002;12(5):301-8.

42. Wirnitzer KC, Faulhaber M. Hemoglobin and hematocrit during an 8 day mountainbike race: A field study. Journal of sports science \& medicine. 2007;6(2):265.

43. Van Wyk DV, Lambert MI. Recovery strategies implemented by sport support staff of elite rugby players in South Africa. South African Journal of Physiotherapy. 2009;65(1):41-6.

44. Nageswari K, Banerjee R, Gupte R, Puniyani R. Effects of exercise on rheological and microcirculatory parameters. Clinical hemorheology and microcirculation. 2000;23(2-4):243-7.

45. Natale VM, Brenner IK, Moldoveanu AI, Vasiliou P, Shek P, Shephard RJ. Effects of three different types of exercise on blood leukocyte count during and following exercise. Sao Paulo Medical Journal. 2003;121(1):09-14.

46. Skarpańska-Stejnborn A, Basta P, Trzeciak J, Szcześniak-Pilaczyńska Ł. Effect of intense physical exercise on hepcidin levels and selected parameters of iron metabolism in rowing athletes. European journal of applied physiology. 2015;115(2):345-51. 